\title{
D-4F increases microRNA-124a and reduces neuroinflammation in diabetic stroke rats
}

\author{
Ruizhuo Ning ${ }^{1,2, *}$, Poornima Venkat ${ }^{1, *}$, Michael Chopp ${ }^{1,3}$, Alex Zacharek ${ }^{1}$, Tao Yan ${ }^{4}$, \\ Xu Cui ${ }^{1}$, Don Seyfried ${ }^{1}$ and Jieli Chen ${ }^{1,4}$ \\ ${ }^{1}$ Department of Neurology, Henry Ford Hospital, Detroit, MI, USA \\ ${ }^{2}$ Department of Neurology, First Hospital Harbin, Harbin, China \\ ${ }^{3}$ Department of Physics, Oakland University, Rochester, MI, USA \\ ${ }^{4}$ Gerontology Institute, Neurology, Tianjin Medical University General Hospital, Tianjin Neurological Institute, Key Laboratory \\ of Post-Neurotrauma Neurorepair and Regeneration in Central Nervous System, Ministry of Education and Tianjin City, \\ Tianjin, China \\ *These authors have contributed equally to this work
}

Correspondence to: Jieli Chen, email: jieli@neuro.hfh.edu

Keywords: stroke; diabetes mellitus; apolipoprotein-A 1; microRNA-124a; neuroinflammation

Received: April 21, $2017 \quad$ Accepted: August 15, $2017 \quad$ Published: September 08, 2017

Copyright: Ning et al. This is an open-access article distributed under the terms of the Creative Commons Attribution License 3.0 (CC BY 3.0), which permits unrestricted use, distribution, and reproduction in any medium, provided the original author and source are credited.

\section{ABSTRACT}

D-4F is an apolipoprotein-A1 mimetic peptide that promotes anti-inflammatory effects. MicroRNA-124 is the most abundant brain-specific microRNA and has antiinflammatory effects. In this study, we investigated the therapeutic efficacy and mechanisms of D-4F treatment of stroke in type one diabetes mellitus (T1DM) rats. Male Wistar rats were induced with T1DM, subjected to embolic middle cerebral artery occlusion and treated with PBS or D-4F (1 mg/ kg i.p.) at 2, 24 and 48 hours after stroke ( $n=8 /$ group). A battery of function tests, brain blood barrier (BBB) integrity, white matter changes and microRNA expression were evaluated in vivo and in vitro. D-4F treatment in T1DM-stroke rats significantly improves functional outcome, decreases BBB leakage, increases tight junction protein expression, decreases white matter damage and inflammatory factor expression, while increasing anti-inflammatory M2 macrophage polarization in the ischemic brain. D-4F significantly increases microRNA124a expression, and decreases matrix metalloproteinase-9, tumor necrosis factor-a and toll-like receptor-4 gene expression in the ischemic brain, and in primary cortical neuronal and microglial cultures. Inhibition of microRNA-124 in cultured primary cortical neurons and microglia attenuates $D-4 F$ induced anti-inflammatory effects and M2 macrophage polarization. D-4F treatment of T1DM-stroke increases microRNA-124 expression, promotes anti-inflammatory effects and M2 macrophage polarization, which may contribute to D-4F-induced improvement in neurological function, and $B B B$ and white matter integrity.

\section{INTRODUCTION}

Diabetes mellitus (DM) patients suffer from a 3-4 fold higher risk of stroke and a worse vascular prognosis compared to non-DM patients $[1,2]$. In DM patients, treatment of stroke with tPA (tissue plasminogen activator) increases the risk of death and spontaneous intra-cerebral hemorrhage [3]. Compared to non-DM stroke rodents, DM- stroke rodents suffer increased inflammatory effects in the ischemic brain, exacerbated proinflammatory responses, and increased release of cytotoxic enzymes, which together increase BBB leakage and brain hemorrhage [3, 4]. DM rats treated with tPA suffer from increased lesion volume, blood brain barrier (BBB) leakage, brain hemorrhagic transformation as well as worse functional outcome $[3,5-$ 7]. Therefore, it is important to develop and test therapeutic 
approaches to specifically reduce neurological deficits after stroke in the DM population.

MicroRNAs (miR) are short sequences of noncoding RNA that can regulate several genes, pathways, and biological networks by acting in concert with other miRs or as stand-alone mediators [8]. In the pathogenesis of stroke, miRs are emerging as mediators of neurodegeneration and neuroinflammation [8, 9]. Among the known miRs, miR-124a is the most abundant brain specific miR, and miR-124a promotes neuronal differentiation during central nervous system (CNS) development [10]. MiR-124a is highly expressed by resident microglia in the CNS, mediates microglial quiescence in the CNS, and has anti-inflammatory effects $[11,12]$. In patients with stroke, a significant decrease in serum miR-124 expression was found within 24 hours post stroke, and decreased miR-124 correlated with increased infarct volume and neuroinflammatory factor matrix metalloproteinase 9 (MMP9) expression [13]. MiR124 up-regulation also decreases other neuroinflammatory factors such as tumor necrosis factor- $\alpha(\mathrm{TNF} \alpha)[14]$ and tolllike receptors (TLR) [15]. Additionally, miR-124 promotes macrophage polarization by decreasing the proinflammatory M1 phenotype and increasing the anti-inflammatory M2 phenotype [16].

In the pathogenesis of DM, and in DM-stroke complications, dysfunction of high-density lipoprotein (HDL) cholesterol increases inflammation [17], and the activated inflammatory responses induce extensive vascular damage [18]. Many of HDL's atheroprotective functions are due to Apolipoprotein A-1 (ApoA-1) [19]. ApoA-1 is widely studied as a mediator of cholesterol efflux and for its use as an anti-inflammatory agent. In a rat DM model, oral administration of D-4F, an ApoA-I mimetic peptide, enhances the functionality of the HDL particle without increasing serum HDL-C levels [20], promotes the conversion of HDL from a proinflammatory to an anti-inflammatory state [21, 22], and improves vascular reactivity [23]. To date, there are no investigations whether D-4F treatment in the DM-stroke population can promote functional outcome, and on the mechanisms of D-4F induced beneficial effects. In this study, we investigate whether $\mathrm{D}-4 \mathrm{~F}$ treatment of stroke promotes miR-124a expression, and modulates neuroinflammatory effects and improves functional outcome after stroke in type one DM (T1DM) rats.

\section{RESULTS}

\section{Stroke treatment using D-4F in T1DM rats does not decrease lesion volume and brain hemorrhagic transformation, but significantly decreases BBB leakage and improves functional outcome}

To test the effects of D-4F treatment in T1DMstroke rats, a battery of functional tests were performed.
The modified neurological severity score (mNSS) test is a composite test that evaluates motor, sensory, balance and reflex actions. The foot-fault test evaluates sensorimotor function, motor coordination and limb placement deficits during locomotion; while the adhesive removal test evaluates somatosensory deficits. Stroke in T1DM rats significantly induces neurological deficits compared to T1DM rats subject to sham surgery $(n=8 /$ group, ${ }^{*} \mathrm{p}<0.05$, Figure 1a). D-4F treatment in T1DM stroke rats significantly decreases modified neurological severity score at 24 and 48 hours after stroke, improves somatosensory function in the adhesive removal test, and decreases the number of foot-faults in the foot-fault test at 48 hours after stroke ( $\mathrm{n}=8$ /group, ${ }^{*} \mathrm{p}<0.05$, Figure $\left.1 \mathrm{a}\right)$ compared to PBS treated T1DM rats.

To investigate whether $\mathrm{D}-4 \mathrm{~F}$ treatment induced neurological functional improvement may be derived from decreased ischemic burden, hemorrhage or BBB protection, the infarct volume, BBB permeability and hemorrhagic transformation were measured. D-4F treatment in T1DM-stroke rats significantly decreases BBB leakage ( $n=4$ /group, ${ }^{*} p<0.05$, Figure $\left.1 b\right)$ and significantly increases tight junction protein ZO-1 (Zone occluden-1) expression around blood vessels in the ischemic border zone at 48 hours after stroke compared to phosphate buffered saline (PBS) treated T1DM stroke rats ( $n=8$ /group, ${ }^{*} \mathrm{p}<0.05$, Figure $1 \mathrm{c}$ ). BBB leakage was not detected in T1DM-sham control rats. D-4F treatment in T1DM-stroke rats does not decrease brain hemorrhagic transformation ( $n=8 /$ group, Figure $1 \mathrm{~d}$ ) and lesion volume $(n=8 /$ group, Figure 1e) compared to PBS treated T1DM stroke control rats at 48 hours after stroke.

\section{D-4F treatment of stroke in T1DM decreases white matter damage}

To test whether D-4F treatment promotes white matter (WM) remodeling, Bielschowsky silver (BS) and Luxol fast blue (LFB) staining were performed. Stroke in T1DM rats significantly decreases axon (BS, Figure 2a, ${ }^{*} \mathrm{p}<0.05, \mathrm{n}=8$ /group) and myelin (LFB, Figure $2 \mathrm{~b},{ }^{*} \mathrm{p}<0.05$, $\mathrm{n}=8$ /group) density compared to T1DM-sham control rats. D-4F treatment of stroke in T1DM rats significantly increases axon (BS, Figure $2 \mathrm{a}, \mathrm{n}=8$ /group, ${ }^{*} \mathrm{p}<0.05$ ) and myelin (LFB, Figure $2 b, n=8$ /group, ${ }^{*} \mathrm{p}<0.05$ ) density in the ischemic border zone (IBZ) compared to PBS treated T1DM stroke rats at 48 hours after stroke.

\section{D-4F treatment of stroke in T1DM rats significantly decreases inflammatory factor expression and promotes M2 macrophage polarization in the ischemic brain}

To investigate mechanisms by which D-4F decreases BBB leakage and WM damage, we first test whether $\mathrm{D}-4 \mathrm{~F}$ treatment of stroke decreases neuroinflammation 
after stroke in T1DM rats. TLR4, nuclear factor kappalight-chain-enhancer of activated $\mathrm{B}$ cells $(\mathrm{NF} \kappa \mathrm{B})$ and MMP9 expression were measured in the IBZ. D-4F treatment significantly ( $\mathrm{n}=8$ /group, $\left.{ }^{*} \mathrm{p}<0.05\right)$ decreases TLR4 (Figure 3a), MMP9 (Figure 3b) and nuclear NFאB (Figure 3c) expression compared to PBS treated T1DM stroke control rats at 48 hours after stroke. D-4F treatment also significantly $\left(\mathrm{n}=8 /\right.$ group, $\left.{ }^{*} \mathrm{p}<0.05\right)$ promotes $\mathrm{M} 2$ macrophage polarization which is identified by increased CD163 expression (Figure 3d) compared to PBS treated T1DM stroke rats at 48 hours after stroke. Figure 5e shows that CD163 co-localizes with CD68 (expressed on monocytes/macrophages), indicating that CD163 is expressed by macrophages/microglia. Inflammatory factors were not detected in T1DM-sham control group.

Consistent with immunostaining, Western blot assay show that D-4F treatment of T1DM stroke rats decreases TLR4, and nuclear NF $\kappa \mathrm{B}$ expression in the ischemic brain (Figure 4a) compared to PBS treated T1DM stroke control rats. The data indicated that D-4F treatment significantly decreases inflammatory factor expression and increases M2 macrophage expression in the ischemic brain in T1DM stroke.

\section{D-4F treatment of stroke in T1DM rats significantly increases miR-124a expression and decreases inflammatory factor gene expression in the ischemic brain}

MiRs can alter several genes, pathways, and biological networks as well as neuroinflammation [8]. To test whether the anti-inflammatory effects of D-4F are related to $\mathrm{miR}$ expression, expression of miRs (miR124a, miR-126, miR-146a, miR-153, miR-155) related to inflammation, BBB integrity and DM were measured in the ischemic brain of control and D-4F treated T1DM stroke rats. Figure $4 \mathrm{~b}$ shows that D-4F treatment significantly increases miR-124a expression in the ischemic brain at 48 hours after stroke ( $\mathrm{n}=4$ /group, $\left.{ }^{*} \mathrm{p}<0.05\right)$. MiR-124 is known to modulate neuronal and immune processes [24].
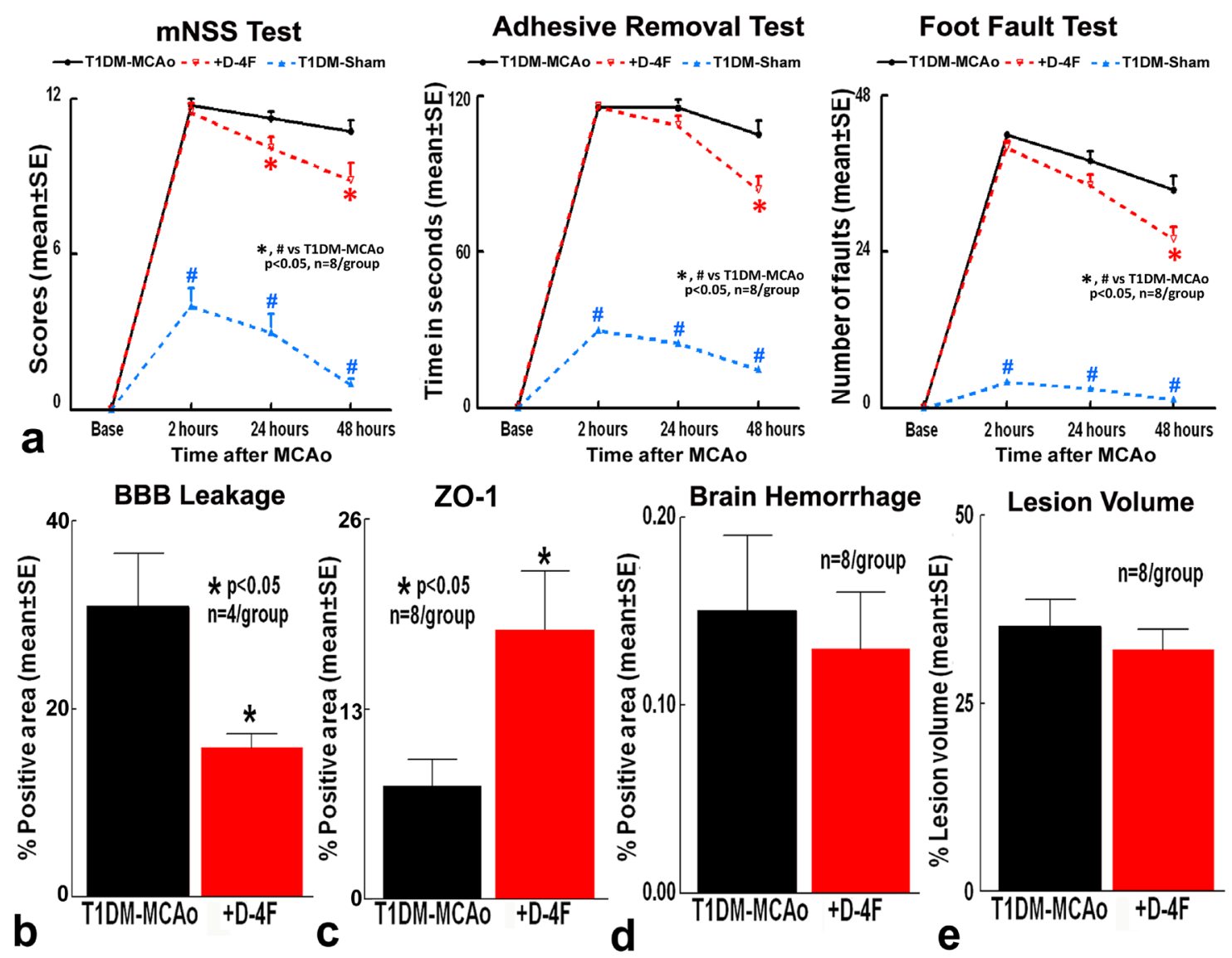

Figure 1: Stroke treatment using D-4F in T1DM rats does not decrease lesion volume and brain hemorrhagic transformation, but significantly decreases BBB leakage and improves functional outcome. Stroke in T1DM rats induces significant neurological deficits compared to T1DM-sham control rats $\left({ }^{*} p<0.05 ; n=8 /\right.$ group). D-4F treatment in T1DM stroke rats significantly: (a) improves neurological functional outcome, (b) decreases BBB leakage, and (c) increases tight junction protein Zonaoccluden-1 (ZO-1) expression around blood vessels, without significantly affecting (d) brain hemorrhage and (e) lesion volume compared to PBS treated T1DM stroke rats ( ${ }^{*} \mathrm{p}<0.05, \mathrm{n}=8$ /group) at 48 hours after stroke. Data are represented as mean $\pm \mathrm{SE}$. 
MiR-124 decreases neuroinflammatory factor such as MMP9, TLR4 and TNF $\alpha[15,25,26]$. Figure 4c shows that D-4F treatment significantly decreases MMP9, TLR4 and TNF $\alpha$ gene expression in the ischemic brain compared to PBS treated T1DM stroke rats $\left(\mathrm{n}=4\right.$ /group, $\left.{ }^{*} \mathrm{p}<0.05\right)$. These data indicate that $\mathrm{D}-4 \mathrm{~F}$ treatment of stroke in T1DM rats increases miR-124a expression, and decreases inflammatory factor gene expression in the ischemic brain.

\section{D-4F decreases inflammatory factor expression in cultured PCN and promotes M2 macrophage polarization in cultured microglia cells in vitro}

MiR-124 is expressed in neurons in the developing and adult nervous systems, and promotes neurite outgrowth during neuronal differentiation [27]. MiR-124 is not only expressed in neurons, but is also expressed in microglia and is a key regulator of microglial quiescence in the CNS [11]. To further test whether D-4F treatment induced anti-inflammatory effects are derived from increased miR-124 activity, primary cortical neuron (PCN) and primary microglia cell cultures subjected to high glucose and oxygen glucose deprivation (OGD) conditions were employed. D-4F treatment significantly increases miR-124a gene expression in cultured PCN and microglial cells compared to non-treatment control (Figure 5a, $\left.{ }^{*} \mathrm{p}<0.05\right)$. In PCN cultures, D-4F treatment significantly decreases TNF $\alpha$, MMP9 and TLR4 expression compared to non-treated control PCN. When miR-124a is inhibited in PCN cells, D-4F induced anti-inflammatory effects were significantly attenuated, as identified by significant increases in TNF $\alpha$, MMP9 and TLR4 gene expression compared to D-4F treated PCN (Figure 5b, ${ }^{*} \mathrm{p}<0.05$ ).

In microglia culture, $\mathrm{D}-4 \mathrm{~F}$ treatment significantly decreases MMP9 and TLR4 expression compared to nontreated control microglia. When miR-124a is inhibited in microglia cells, D-4F induced anti-inflammatory effects were significantly attenuated, as identified by increases in MMP9 gene expression compared to D-4F treated microglia (Figure $5 \mathrm{~d}, \mathrm{p}<0.05$ ). D-4F treatment also significantly decreases M1 microglia and increases M2 macrophage polarization compared to non-treated microglia culture $\left({ }^{*} \mathrm{p}<0.05\right)$. MiR-124 knock down in microglia culture, significantly attenuated D-4F induced M2-macrophage polarization (Figure 5c, ${ }^{*} \mathrm{p}<0.05$ ). These data indicate that miR-124 may at least partially contribute to D-4F induced anti-inflammatory effect and M2 macrophage polarization.

\section{DISCUSSION}

In this study, for the first time to our knowledge, we demonstrate that D-4F treatment of T1DM rats subjected to stroke significantly increases miR-124a expression in the ischemic brain and in cultured PCN and microglial cells, decreases inflammatory factor expression, promotes M2 macrophage polarization, increases tight junction protein expression, decreases BBB leakage, decreases WM damage, and improves neurological functional outcome at 48 hours after stroke. The increase in miR$124 \mathrm{a}$ expression may partially facilitate the decrease of inflammatory responses and promote M2 macrophage polarization in T1DM stroke rats.
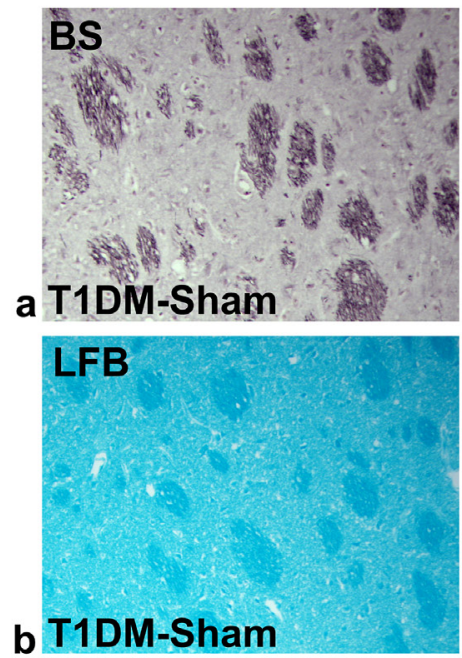
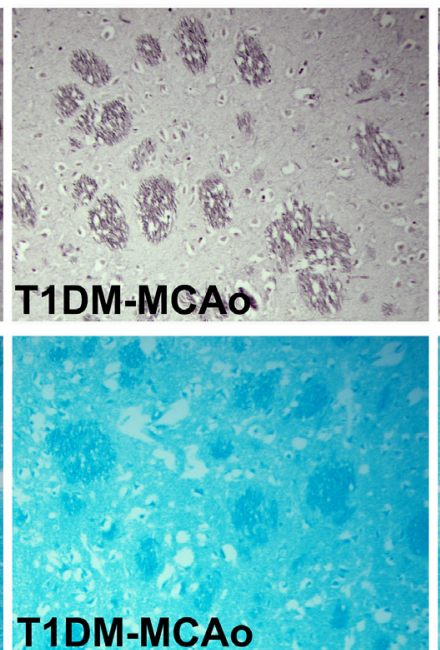
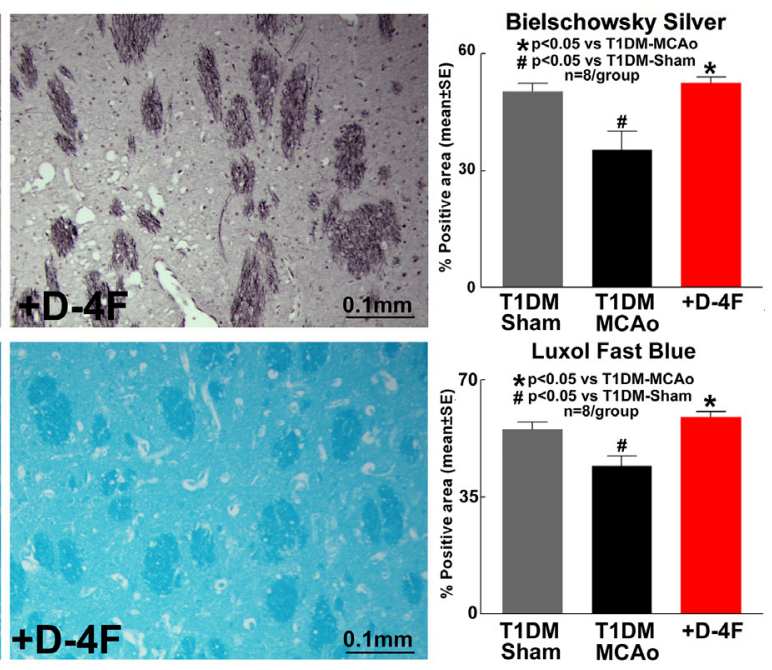

Figure 2: D-4F treatment of stroke in T1DM rats decreases white matter damage. Stroke in T1DM rats significantly decreases axon (Bielschowsky silver staining) and myelin density (Luxol fast blue staining) compared to T1DM-sham control rats ( ${ }^{\#} \mathrm{p}<0.05$; $\mathrm{n}=8$ /group). D-4F treatment of stroke in T1DM rats significantly increases (a) axon density (Bielschowsky silver staining) and (b) myelin density (Luxol fast blue staining) in the ischemic border zone compared to PBS treated T1DM stroke control rats ( ${ }^{*} \mathrm{p}<0.05$, $\mathrm{n}=8 /$ group) at 48 hours after stroke. Data are represented as mean $\pm \mathrm{SE}$. 
Increased BBB leakage and inflammatory responses in DM stroke rats are associated with worse functional outcome [3, 28]. In DM stroke patients, microglial activation is increased within minutes of ischemia onset and triggers the production of inflammatory cytokines, including MMP9 and TNFa, which exacerbate tissue damage [29]. The rapid activation of resident microglial cells is followed by the infiltration of blood-derived immune cells into the ischemic brain tissue within hours to a few days. The cerebrovascular endothelium is transformed from a quiescent state into a proinflammatory state by a cascade of molecular events that follow focal

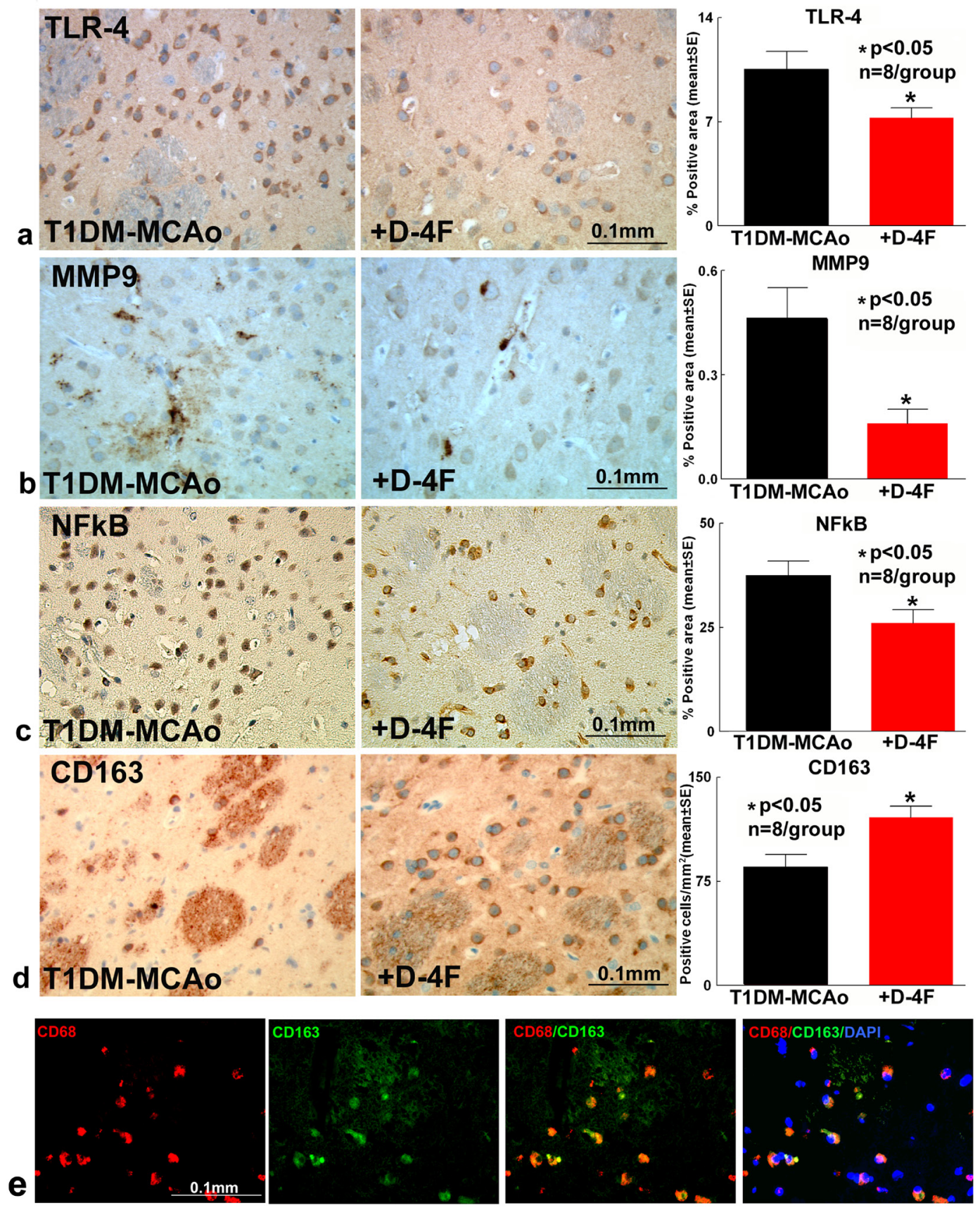

Figure 3: D-4F treatment of stroke in T1DM rats significantly decreases inflammatory factor expression and promotes M2 macrophage polarization in the ischemic brain. At 48 hours after stroke, D-4F treatment significantly decreases (a) TLR4, (b) MMP9 and (c) NFkB expression compared to PBS treated T1DM stroke control rats $\left({ }^{*} \mathrm{p}<0.05, \mathrm{n}=8 /\right.$ group). (d) D-4F treatment also significantly promotes M2 macrophage polarization which is identified by increased CD163 expression compared to PBS treated T1DM stroke control rats $\left({ }^{*} \mathrm{p}<0.05, \mathrm{n}=8 /\right.$ group). Data are represented as mean $\pm \mathrm{SE}$. (e) CD163 co-localizes with CD68 indicating that CD163 is expressed by macrophages/microglia. DAPI is a nuclear stain. 
brain ischemia. Microglial cells and blood-derived monocytes/macrophages play key roles in inflammation during the onset as well as during the progressive aggravation of stroke lesions [30]. In this study, we found that D-4F treatment in T1DM rats subjected to stroke significantly decreases BBB leakage, increases tight junction protein expression, and reduces inflammatory factor expression such as MMP9, TNF $\alpha$ and NF $\mathrm{B}$ in the ischemic brain, as well as improves functional outcome compared to PBS treated T1DM stroke rats at 48 hours after stroke. Therefore, control of BBB leakage and inflammatory responses may play an important role in $\mathrm{D}-4 \mathrm{~F}$ induced improvement in functional outcome after stroke in T1DM rats.

The mechanism of D-4F induced decrease in BBB leakage is not clear. Tight junctions provide barriers between adjacent brain capillary endothelial cells at the BBB and stabilize blood vessels [31]. ZO-1 is a functionally critical tight junction protein [32]. In this study, we found that D-4F treatment significantly
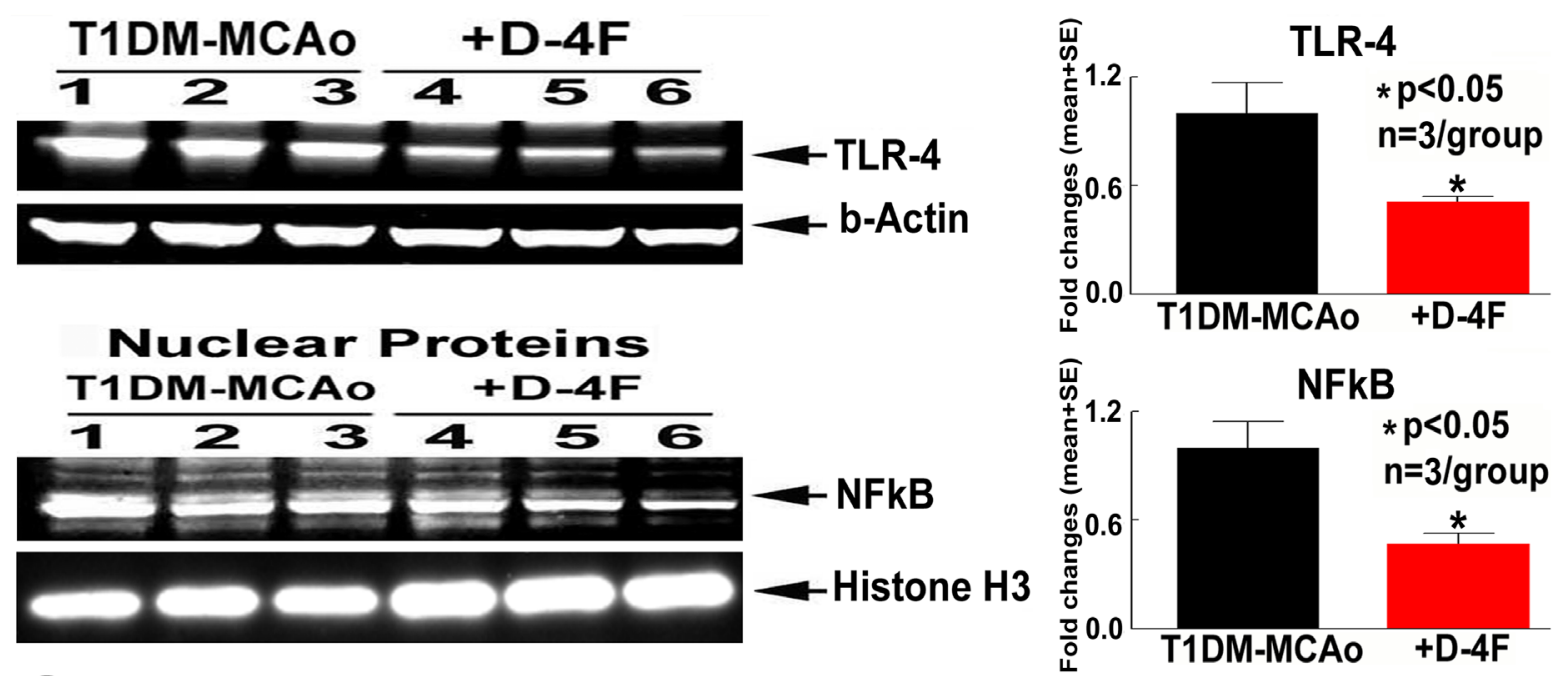

a

miR Expression (IBZ)

T1DM-MCAo + +D4F

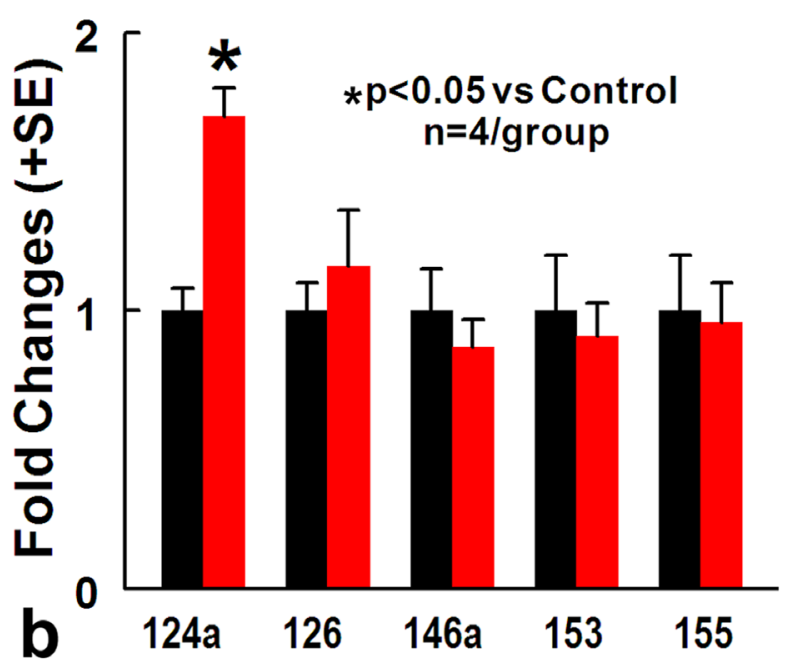

mRNA Expression (IBZ)

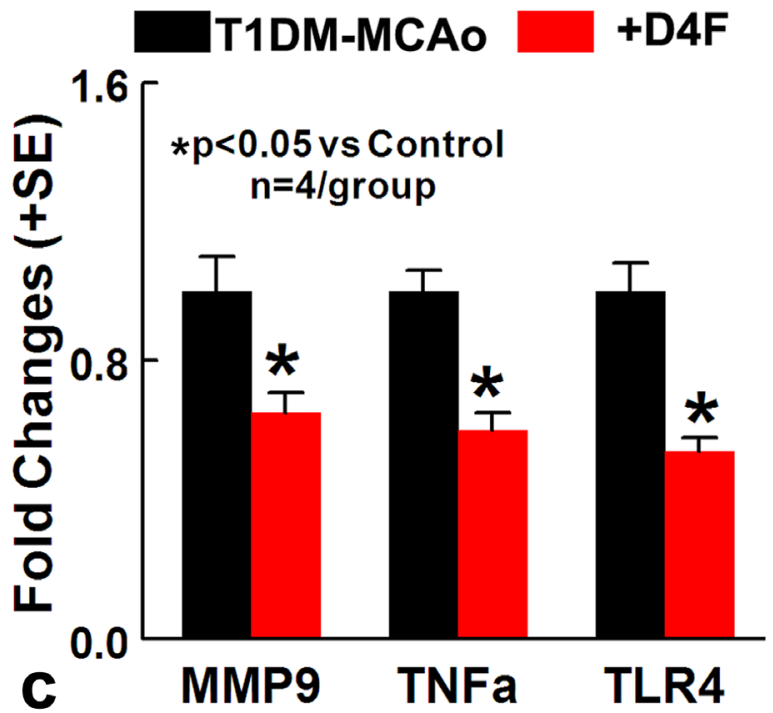

Figure 4: D-4F treatment of stroke in T1DM rats significantly decreases inflammatory factor expression and increases miR-124a expression. (a) Western blot assay showing that D-4F treatment of T1DM stroke rats decreases TLR4, and nuclear NFKB expression in the ischemic brain compared to PBS treated T1DM stroke control rats ( ${ }^{*} \mathrm{p}<0.05, \mathrm{n}=3$ /group). (b) D-4F treatment significantly increases miR-124a expression in the ischemic brain at 48 hours after stroke ( ${ }^{*} \mathrm{p}<0.05, \mathrm{n}=4 /$ group). (c) $\mathrm{D}-4 \mathrm{~F}$ treatment significantly decreases MMP9, TLR4 and TNF $\alpha$ gene expression in the ischemic brain compared to PBS treated T1DM stroke control rats at 48 hours after stroke $\left({ }^{*} \mathrm{p}<0.05, \mathrm{n}=4\right.$ /group). Data are represented as mean $\pm \mathrm{SE}$. 
increases ZO-1 expression around blood vessels in the IBZ , which may contribute to the improved BBB integrity and function compared to PBS treated T1DM-stroke rats. DMstroke significantly increases MMP9 activity compared to non-DM stroke, and MMP9 has been specifically implicated in the disruption of the BBB and neuronal cell death following cerebral ischemia [33, 34]. MMP9 is a neuroinflammatory factor that is elevated after stroke, and has been associated with WM injury, BBB disruption, worse neurological deficits and increased infarct volume after stroke $[8,35]$. Diabetes induces an imbalance in the MMPs/TIMPs (tissue inhibitors of metalloproteinases) cascade and increases MMP9 which results in an increased degradation of occludin and collagen-IV, and subsequently increases $\mathrm{BBB}$ permeability facilitating increased infiltration of neutrophils into the infarct area [33]. In this study, we found that D-4F treatment significantly decreases MMP9 expression in the ischemic brain, which may contribute to the decreased BBB leakage.

BBB leakage and inflammation are closely related with WM damage after stroke [36, 37]. DM-stroke exacerbates BBB disruption and increases the expression of inflammatory factors including high mobility group box 1 (HMGB1), receptor for advanced glycation endproducts (RAGE), MMP9 and TLR4 in the ischemic brain, which have been correlated with increased WM

\section{MiR-124a Expression}

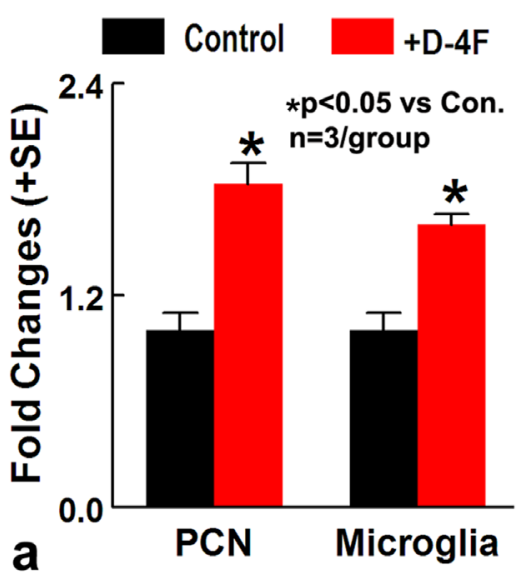

PCN Gene Expression $\square$ Con. $\square+\mathrm{D}-4 \mathrm{~F} \square$ miR-124-I-+D-4F

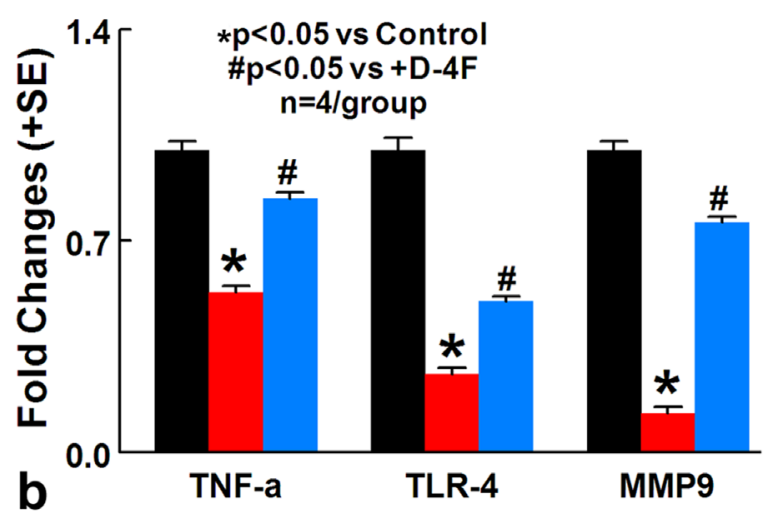

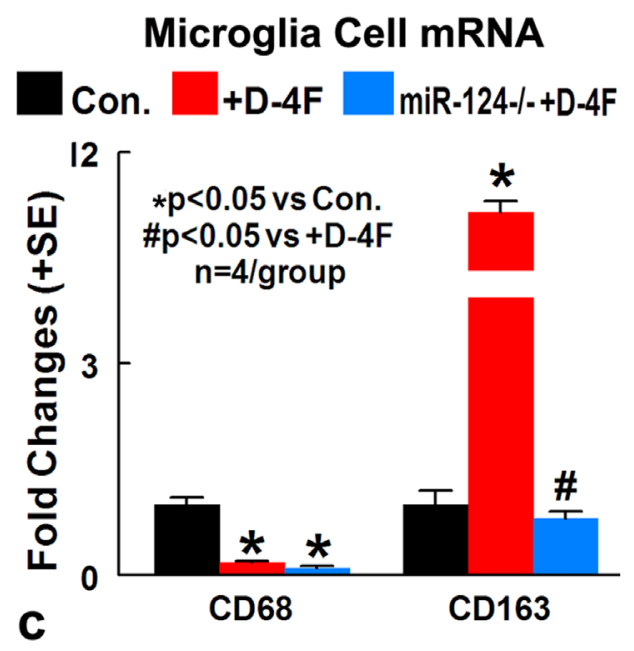

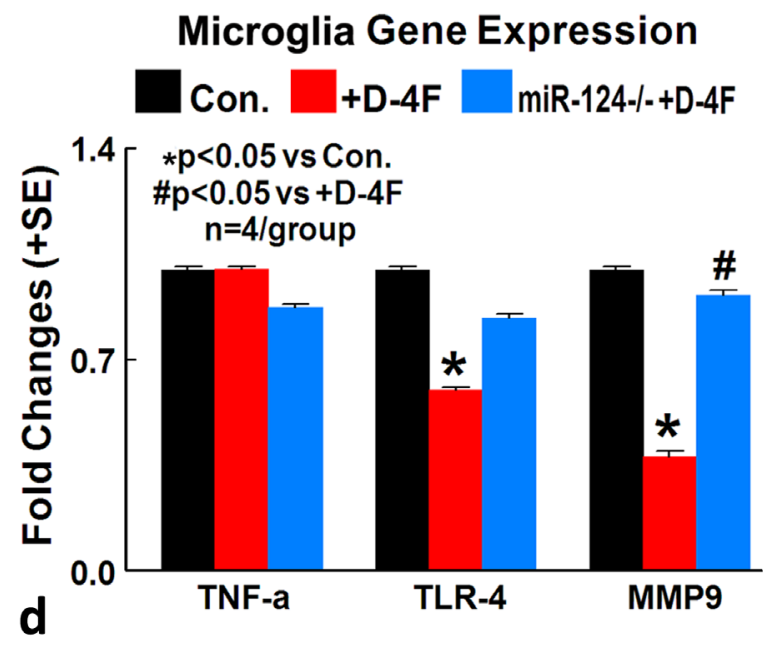

Figure 5: In vitro, D-4F decreases inflammatory factor expression in cultured PCN and promotes M2 macrophage polarization in cultured microglia cells under conditions of high glucose and OGD. (a) D-4F treatment significantly increases miR-124a gene expression in cultured PCN and microglial cell under conditions of high glucose and OGD, compared to nontreatment control ( ${ }^{*} \mathrm{p}<0.05, \mathrm{n}=3$ /group). (b) MiR-124a inhibition in PCN cells significantly attenuates D-4F induced anti-inflammatory effects identified by significant increases in TNF $\alpha$, MMP9 and TLR4 gene expression compared to D-4F treated PCN (" $\mathrm{p}<0.05$ vs. control, $" \mathrm{p}<0.05$ vs. D-4F treatment, $\mathrm{n}=4$ /group). (c) MiR-124 knock down in microglia culture significantly attenuates $\mathrm{D}-4 \mathrm{~F}$ induced M2-macrophage polarization ( ${ }^{*} \mathrm{p}<0.05$ vs. control, ${ }^{*} \mathrm{p}<0.05$ vs. D-4F treatment, $\mathrm{n}=4$ /group). (d) MiR-124a inhibition in microglial cells significantly attenuates D-4F induced anti-inflammatory effects identified by increases in MMP9 $\left({ }^{*} \mathrm{p}<0.05\right.$ vs. control, ${ }^{*} \mathrm{p}<0.05 \mathrm{vs}$. D-4F treatment, $\mathrm{n}=4$ /group) and TLR4 gene expression compared to D-4F treated microglia. Data are represented as mean $\pm \mathrm{SE}$. 
damage in DM stroke animals [28, 34]. In this study, we found that D-4F treatment not only decreases BBB leakage and inflammatory factor expression, but also decreases WM damage identified by increased axon and myelin density in the ischemic boundary zone in T1DM rats. in vitro studies also indicate that $\mathrm{D}-4 \mathrm{~F}$ decreases PCN inflammatory factor expression such as TNF $\alpha$, MMP9 and TLR4.

Stroke induces inflammatory processes, characterized by rapid microglial activation, secretion of proinflammatory factors, and infiltration of inflammatory cells such as neutrophils, monocytes and macrophages into the ischemic brain tissue [38]. Abnormalities in innate immunity leading to diabetic complications have also been implicated in worse functional outcome after stroke [39, 40]. Macrophages constitute about $70 \%$ of infiltrating cells in the CNS inflammatory lesions [41]. "Classically activated" proinflammatory (M1) macrophages are the major inflammatory cells in the brain, and exert a neurotoxic function through the production of cytokines (Interleukins (IL)-1 $\beta$ and 6, TNF $\alpha$ ) [42, 43]. "Alternatively activated" anti-inflammatory (M2) macrophages typically express Arginase I, mannose receptor (CD206) and CD163 [44-49], have a neurotrophic role and facilitate axon growth [50]. In this study, we found that D-4F treatment significantly increases M2 macrophage polarization compared to PBS treated T1DM stroke rats. in vitro, we also found that D-4F treatment significantly decreases inflammatory factor MMP9, TNF $\alpha$ and TLR4 expression as well as promotes M2 macrophage polarization in cultured microglia cells subjected to high glucose and hypoxic conditions. However, the mechanism of D-4F induced M2 macrophage polarization is not completely understood.

MiR-124is a critical promoter of multifaceted anti-inflammatory effects by inhibiting the production of proinflammatory cytokines such as IL6 and TNF $\alpha$ [27]. In vitro, miR-124 expression is down-regulated by activated microglia, and in the CNS, miR-124 levels correlate inversely with the state of microglial activation and macrophages [11]. MiR-124 also promotes neuronmicroglia interaction and desensitizes neurons in an inflammatory environment [51]. Increasing miR-124by injection significantly increases neuronal survival and increases number of M2-like polarized microglia/ macrophages [52], and suppresses experimental autoimmune encephalomyelitis symptoms and leukocyte infiltration in the CNS [11]. Increasing miR-124 expression in the brain of mice subjected to stroke via intravenous injection of miR-124 agomir significantly decreases infarct volume and attenuates neuronal cell death and late apoptosis [53]. Loss ofmiR-124decreases oligodendrocyte cell numbers and myelination of axonal projections in the ventral hindbrain [54]. In this study, we found that D-4F significantly increases miR124a expression and decreases its target gene MMP9,
TLR4 and TNF $\alpha$, while promoting M2 macrophage polarization in the ischemic brain and in cultured PCN and microglia cells subjected to high glucose and OGD conditions. Inhibition of miR-124a expression in PCN attenuates $\mathrm{D}-4 \mathrm{~F}$ induced anti-inflammatory effects. Inhibition of miR-124 in cultured microglia significantly decreases D-4F induced M2 macrophage polarization and attenuated the decreased MMP9 expression. Therefore, increase of miR-124a expression by D-4F treatment may promote M2 macrophage polarization and antiinflammatory effects.

\section{Limitations}

In this study, we show that $\mathrm{D}-4 \mathrm{~F}$ promotes beneficial effects after stroke in T1DM rats, which may at least in part be attributed to up regulation of miR-124a. In this study, we found that D-4F decreases MMP9, TLR4 and TNFa inflammatory factor expression; however, inhibition of miR-124 only partially attenuates D-4F-induced decreasing MMP9 expression in cultured microglia. However, several other miR's may also act in concert to promote D-4F induced beneficial effects. Other miRs may also mediate D-4F induced anti-inflammatory effects. In addition, miR-124 regulates many target genes as well as inflammatory factors. MiR-124 directly or indirectly regulates MMP9, TNFa and TLR4 warranted investigated in future study. Causal mechanistic studies relating modulation of miR-124a by D-4F are warranted, as are investigations of long term effects of D-4F treatment in T1DM stroke.

\section{Conclusions}

Treatment of stroke in T1DM rats with D-4F increases miR-124a expression, decreases neuroinflammatory responses and promotes M2 macrophage polarization which, in concert, may contribute towards decreasing BBB leakage and WM damage thereby improving functional outcome.

\section{MATERIALS AND METHODS}

All experimental procedures were carried out in accordance with the NIH Guide for the Care and Use of Laboratory Animals and approved by the Institutional Animal Care and Use Committee of Henry Ford Hospital.

Adult Male Wistar rats (225-250 g, 3 months) were used to induce T1DM by a single intraperitoneal (i.p) injection of $60 \mathrm{mg} / \mathrm{kg}$ Streptozotocin (Sigma) [55]. Two weeks later, fasting blood glucose was tested using a glucose analyzer (Accu-Chek Compact System; Roche Diagnostics). Animals with fasting blood glucose $>300$ $\mathrm{mg} / \mathrm{dl}$ were defined diabetic and included in the study. 


\section{Embolic middle cerebral artery occlusion (MCAo) model and experimental groups}

T1DM rats were anesthetized with $2 \%$ isoflurane in a jar for pre anesthetic, and spontaneously respired with $1.5 \%$ isoflurane in $2: 1 \mathrm{~N}_{2} \mathrm{O}: \mathrm{O}_{2}$ mixture using a facemask connected and regulated with a modified FLUOTEC 3 Vaporizer (Fraser Harlake). Rectal temperature was maintained at $37^{\circ} \mathrm{C}$ throughout the surgical procedure using a feedback regulated water heating system. Embolic MCAo was performed as previously described [56]. Rats were randomized and assigned to different groups ( $\mathrm{n}=11$ /group) and were treated with 1) PBS (2 ml, i.p.); 2) D-4F (1 mg/kg, i.p.) at 2 hours, 24 hours and 48 hours after MCAo. The dose $(1 \mathrm{mg} / \mathrm{kg}$, i.p injection) of D-4F was selected according previous publication [21]. After a mortality of $30 \%$ in each group; $n=8 /$ group was employed for further analysis. Sham surgery was performed in the same way as the MCAo model without injecting the emboli ( $\mathrm{n}=8 /$ group).

\section{Neurological functional tests}

At 2 hours, 24 hours and 48 hours after MCAo, an investigator who was blinded to the experimental groups performed mNSS evaluation, adhesive removal test and foot-fault test, as previously described. The testing procedure is briefly described below:

a) mNSS test $[2,57]$ : In the mNSS test, motor, sensory, balance and reflex actions are tested. The absence of a tested reflex or abnormal response is scored as one point and neurological function is scored between 0-18. An animal with a score of 0 indicates no neurological deficits, and an animal receiving a maximum score of 18 indicates maximum neurological deficits.

b) Foot-fault test [58]: This test evaluates sensorimotor function, motor coordination and limb placing deficits during locomotion [59]. The testing equipment consists of an elevated grid floor $(45 \mathrm{~cm} \times 30$ $\mathrm{cm}), 2.5 \mathrm{~cm}$ higher than a solid base floor, with $2.5 \mathrm{~cm}$ $\times 2.5 \mathrm{~cm}$ diameter grid spacing. The animal is placed on the grid and allowed to move freely. During the animals movement on the wire grid using their paws, a fall or slip through a grid opening due to an inaccurate forelimb placement is recorded as a foot-fault. Data are presented as the percentage of foot-faults of the left paw over a 100 forelimb movements.

c) Adhesive removal test [57]: The adhesive removal test evaluates somatosensory deficits by using 2 small pieces of adhesive-backed paper dots (of equal size, $113.1 \mathrm{~mm}^{2}$ ) as bilateral tactile stimuli occupying the distalradial region on the wrist of each forelimb. The time to remove each stimulus from forelimbs was recorded for 5 trials per day. Individual trials were separated by at least 5 minutes. All animals were familiarized with the testing environment. Prior to stroke surgery, all animals were trained for 3 consecutive days such that rats could remove the stickers within 10 seconds.

\section{Exclusion criteria}

Rats were excluded from the study if they failed to remove the adhesive sticker within 10 seconds during the training sessions, i.e. exhibit pre-operative asymmetries [59]. Rats were also excluded if the mNSS score was less than 6 (possibly small to no lesion, condition improves regardless of treatment) or over 13 (very large lesion, poor survival, condition deteriorates regardless of treatment) at 2 hours after stroke.

\section{BBB leakage measurement}

An additional set of T1DM-MCAo control rats and T1DM-MCAo+D-4F treatment rats ( $\mathrm{n}=4$ /group) were prepared and sacrificed at 48 hours after MCAo. Evansblue dye (2\%) was injected intravenously 4 hours before sacrifice and fluorescence intensity was measured using a microplate fluorescence reader (excitation $620 \mathrm{~nm}$ and emission $680 \mathrm{~nm}$ ) [60]. The amount of extravasated Evans blue dye was quantified as micrograms per ischemic hemisphere [60].

\section{Lesion volume and brain hemorrhage measurement}

All brains were fixed by transcardial perfusion with $0.9 \%$ saline, followed by perfusion and immersion in $4 \%$ paraformaldehyde then embedded in paraffin. Seven coronal sections of tissue were processed and stained with hematoxylin and eosin (H\&E) for calculation of lesion volume and presented as a percentage of the lesion compared with the contra-lateral hemisphere. Brain hemorrhage was measured by using H\&E staining. The percentage areas of petechial and gross hemorrhage were measured in each histological section and summed.

\section{Histological assessments}

A standard block was obtained from the center of the lesion (bregma $-2 \mathrm{~mm} \sim+2 \mathrm{~mm}$ ). A series of $6 \mu \mathrm{m}$ thick sections was cut from the block. Every $10^{\text {th }}$ coronal section for a total 5 sections was used for immunohistochemical staining. Antibodies against ZO-1 (1:50, Zymed) NFkB (1:500; Abcam), TLR4 (1:100; Santa Cruz Biotechnology), MMP9 (1:500, Santa Cruz Biotechnology), CD163 (1:1000, Biorbyt) and CD68 (1:30, Serotec) were used. DAPI was used to stain nuclei. BS staining was used to stain axons and LFB was used to stain myelin as described previously [61]. Control experiments consisted of staining brain coronal tissue sections as outlined above, but nonimmune serum was substituted for the primary antibody. The immunostaining analysis was performed by an investigator blinded to the experimental groups. 


\section{Immunostaining quantification}

Each slide containing 8 fields of view from the IBZ was digitized under a $40 \times$ or $20 \times$ objective (Olympus BX40) interfaced with an MCID image analysis system (Imaging Research). The IBZ is defined as the area surrounding the lesion. The data from five sections and eight regions within each section were averaged to obtain a single value for one animal and presented as percentage of positive area for TLR4, MMP9, BS and LFB, percentage number of nuclear positive cells for NFKB and positive cells number for CD163, respectively. For quantitation of ZO-1 expression, 10 large blood vessels in the IBZ were digitized under $40 \times$ and data presented as percentage of positive area.

\section{Primary cortical neuron culture}

PCNs were harvested from pregnant (day 18) embryonic Wistar rats (Charles River). The cultures were prepared as previously described with some modifications $[62,63]$. Briefly, the embryo cerebral cortex was dissected and dissociated in $\mathrm{Ca}^{2+}$ and $\mathrm{Mg}^{2+}$ free HBSS with $0.125 \%$ trypsin. The cells were plated on poly-d-lysine (Sigma) coated dishes (35 mm, Corning) and initially cultured in DMEM media (Life Technologies) with 5\% fetal bovine serum for 5 hours, then neurobasal growth medium (Life Technologies) with 2\% B-27 (Life Technologies), $2 \mathrm{~mm}$ GlutaMax, and $1 \%$ antibiotic-antimycotic was used.

\section{Primary microglia cell culture}

Primary microglial cells were harvested following previously published methods [64]. Primary cortical tissue was harvested from pregnant Wistar day 18 rats (Charles River Laboratories). The cerebral cortex were dissected from the embryos and broken up in calcium and magnesium free HBSS with $0.125 \%$ trypsin for 10 minutes and then mechanically disassociated with a pipette ( $\sim 20$ strokes). The cells were filtered through a 40 $\mu \mathrm{m}$ cell strainer and plated at $5 \times 10^{6}$ cells per T75 flask. The cells were cultured in $10 \mathrm{ml}$ of growth media, DMEM media (Life Technologies) with 10\% Fetal Bovine Serum (Life Technologies), with the media changed ever 2-3 days for ten days. On the tenth day the media was removed and $10 \mathrm{ml}$ of fresh growth media was added, the cap of the flask was wrapped in Parafilm to prevent atmosphere exchange, and the flask was shaken at $210 \mathrm{rpm}$ for 1 hour on a Benchmark Incu-Shaker. After the shaking the media was collected and centrifuged to harvest the suspended microglia. Fresh growth media was added to the flask and the cells were allowed to culture for an additional week for a second shaking, to harvest more microglia. The populations obtained using this method were $90-95 \%$ pure for macrophage/microglia cell specific marker (Iba1). The harvested cells were then used for the studies, with no additional passages.

\section{MiR-124 knockdown in PCN and microglia using electroporation}

To test effects of miR-124 in regulation of antiinflammatory and M2 macrophage polarization, miR124 inhibitor was employed to knockdown of PCN and microglia miR-124 expression. Briefly, a mixture of 100 $\mu 1$ Ingenio Electroporation Solution (Mirus) and $5 \mathrm{nmol}$ rno-miR-124-3p inhibitor or mimic (GE Dharmacon) was prepared. Cells were harvested and $1-2 \times 10^{6}$ were resuspended in the electroporation solution. The solution was loaded into Ingenio cuvettes with a $0.2 \mathrm{~cm}$ gap (Mirus) which were stored on ice until loaded into the Amaxa Nucleofection machine (Lonza) and electroporated using program Y-01. After electroporation cells were removed from the cuvettes and put into culture and allowed to grow for 48 hours before being used in the studies.

\section{Oxygen glucose deprivation (OGD)}

To subject cells cultures to OGD, serum and glucose free media was used. Cells were placed in a hypoxia chamber (Forma Anaerobic System; Thermo Scientific) with $37^{\circ} \mathrm{C}$ incubator for 2 hours. After 2 hours, the cells were removed and replaced in high glucose cultured media $(37.5 \mu \mathrm{M})$.

\section{Experimental treatment group in vitro}

Cultured OGD-PCN and OGD-microglia were treated with: 1) non-treated control; 2) D-4F (50 ng/ml and $100 \mathrm{ng} / \mathrm{ml}) ; 3$ ) miR-124-knockdown (miR-124-/-)+D$4 \mathrm{~F}$ treatment. Gene expression using PCR and miR-124 expression was measured.

\section{Real time PCR}

Total RNA was isolated with TRIzol (Invitrogen), then make cDNA using the M-MLV (Invitrogen) standard protocol. $2 \mu 1 \mathrm{cDNA}$ was used to run a quantitative PCR using the SYBR Green real time PCR method using the following primers (Invitrogen).

TNFa: FWD: TACTCCCAGGTTCTCTTCAAGG; REV: GGAGGTTGACTTTCTCCTGGTA; MMP9:

FWD: ATCTCTTCTAGAGACTGGGAAGGAG; REV: AAGCTGATTGACTAAAGTAGCTGGA. TLR4: FWD: TCTAACTTCCCTCCTGAGATGG REV: ACTGGCTAGAGAGCAAGAGGAA CD68: FWD: TGTTCAGCTCCAAGCCCAAA REV: GTACCGTCACAACCTCCCTG CD163: FWD: TGCTGTCACTAACGCTCCTG REV: TCATTCATGCTCCAGCCGTT

The PCR was run in a ViiA 7 machine (Applied Biosystems) using a 3-stage program provided by the manufacturer, as follows; 2 minutes at $50^{\circ} \mathrm{C}, 10$ minutes at $95^{\circ} \mathrm{C}$, and then 40 cycles of 15 seconds at $95^{\circ} \mathrm{C}$ 
and 1 minute at $60^{\circ} \mathrm{C}$. Glyceraldehyde-3-phosphate dehydrogenase (GAPDH) was used as the housekeeping gene for normalization. Each sample was tested in triplicate, and analysis of relative gene expression data using the $2^{-\triangle \Delta C T}$ method.

\section{MiR measurement}

Total RNA was isolated with TRIzol (Invitrogen), then make cDNA using the TaqMan miR Reverse transcription kit (Applied Biosystems) following standard protocol. $4 \mu \mathrm{l}$ of cDNA it was used to run a TaqMan PCR following standard protocol, and using miR primers for miR-124a (Applied Biosystems).

\section{Western blot assay}

Protein was isolated from samples using Trizol (Invitrogen). Protein concentration was measured using the BCA kit (Thermo Scientific) and $40 \mu \mathrm{g}$ of protein/ lane loaded in a 10\% SDS PAGE precast gel (Invitrogen). Gel was transferred using the iBlot transfer system (Invitrogen). Nitrocellulose membrane was blocked in 2\% I-Block (Applied Biosystems) in 1×TBS-T for one hour, and then either b-actin (Abcam, 1:10,000), Histone H3 (Cell Signaling, 1:1000), RAGE (R\&D Biosystems, 1:500), TLR4 (Santa Cruz, 1:500), or NFאB (Abcam, $1: 1,000)$ was used. Secondary antibodies (anti-mouse, Jackson ImmunoResearch) were added at 1:1,000 dilution in $2 \%$ I-Block in $1 \times$ TBS-T on a room temperature. The membranes were washed with $1 \times \mathrm{TBS}-\mathrm{T}$, and then Luminol Reagent (Santa Cruz) was added. The membranes were then developed using a FluorChem E Imager system (ProteinSimple).

\section{Statistical analysis}

One-way Analysis of Variance (ANOVA) was used for the evaluation of functional outcome and histology, respectively. "Contrast/estimate" statement was used to test the group difference. If an overall treatment group effect was detected at $\mathrm{p}<0.05$, pair-wise comparisons were made. All data are presented as mean \pm standard error (SE).

\section{Abbreviations}

ANOVA: One-way Analysis of Variance; ApoA1: Apolipoprotein A-1; BBB: Blood brain barrier; BS: Bielschowsky silver; CNS: Central nervous system; DM: Diabetes mellitus; FWD: Forward; GAPDH: Glyceraldehyde-3-phosphate dehydrogenase; H\&E: Hematoxylin and eosin; HDL: High-density lipoprotein; HMGB1: High mobility group box 1; IBZ: Ischemic border zone; IL: Interleukin; LFB: Luxol fast blue; MCAo: Middle Cerebral Artery Occlusion; MiR: MicroRNA; MMP9: Matrix metalloproteinase 9; mNSS: Modified neurological severity score; NFкB: Nuclear factor kappalight-chain-enhancer of activated B cells; OGD: Oxygen glucose deprivation; PBS: Phosphate buffered saline; PCN: Primary cortical neuron; PCR: Polymerase chain reaction; RAGE: Receptor for advanced glycation endproducts; REV: Reverse; SE: Standard error; T1DM: Type one DM; TIMPs: Tissue inhibitors of metalloproteinases; TLR4: Toll-like receptor-4; TNF $\alpha$ : Tumor necrosis factor- $\alpha$; tPA: Tissue plasminogen activator; WM: White matter; ZO-1: Zona occluden-1.

\section{Author contributions}

$\mathrm{PV}, \mathrm{MC}$ and JC wrote the manuscript. PV and JC prepared the figures. RN, PV, AZ, TY, XC and DS conducted experiments, collected and analyzed data. All authors have approved the manuscript.

\section{ACKNOWLEDGMENTS}

The authors sincerely thank Cynthia Roberts, Julie Landschoot-Ward, Qinge Lu and Sutapa Santra for their technical assistance.

\section{CONFLICTS OF INTEREST}

The authors have no conflicts of interest to declare.

\section{FUNDING}

This work was supported by National Institute of Neurological Disorders and Stroke R01 NS08307801A1 (J.C), RO1 NS099030-01 (J.C), R01 NS097747 (J.C), R01NS092917 (X.C); American heart association 17POST33410580 (P.V); and by the National Natural Science Foundation of China grants 81300993 (T.Y) and 81571145 (T.Y).

\section{REFERENCES}

1. Putaala J, Liebkind R, Gordin D, Thorn LM, Haapaniemi E, Forsblom C, Groop PH, Kaste M, Tatlisumak T. Diabetes mellitus and ischemic stroke in the young: clinical features and long-term prognosis. Neurology. 2011; 76: 1831-7. https://doi.org/10.1212/WNL.0b013e31821 cccc2.

2. Yan T, Venkat P, Ye X, Chopp M, Zacharek A, Ning R, Cui Y, Roberts C, Kuzmin-Nichols N, Sanberg CD, Chen J. HUCBCs increase angiopoietin 1 and induce neurorestorative effects after stroke in T1DM rats. CNS Neurosci Ther. 2014; 20: 935-44. https://doi.org/10.1111/ cns. 12307.

3. Ning $R$, Chopp $M$, Yan $T$, Zacharek A, Zhang C, Roberts C, Cui X, Lu M, Chen J. Tissue plasminogen activator treatment of stroke in type-1 diabetes rats. 
Neuroscience. 2012; 222: 326-32. https://doi.org/10.1016/j. neuroscience.2012.07.018.

4. Ning R, Chopp M, Zacharek A, Yan T, Zhang C, Roberts $\mathrm{C}, \mathrm{Lu} \mathrm{M}$, Chen J. Neamine induces neuroprotection after acute ischemic stroke in type one diabetic rats. Neuroscience. 2014; 257: 76-85. https://doi.org/10.1016/j. neuroscience.2013.10.071.

5. Fan X, Qiu J, Yu Z, Dai H, Singhal AB, Lo EH, Wang X. A rat model of studying tissue-type plasminogen activator thrombolysis in ischemic stroke with diabetes. Stroke. 2012; 43: 567-70. https://doi.org/10.1161/strokeaha.111.635250.

6. Chen J, Ye X, Yan T, Zhang C, Yang XP, Cui X, Cui Y, Zacharek A, Roberts C, Liu X, Dai X, Lu M, Chopp M. Adverse effects of bone marrow stromal cell treatment of stroke in diabetic rats. Stroke. 2011; 42: 3551-8. https://doi. org/10.1161/strokeaha.111.627174.

7. Ye X, Chopp M, Cui X, Zacharek A, Cui Y, Yan T, Shehadah A, Roberts C, Liu X, Lu M, Chen J. Niaspan enhances vascular remodeling after stroke in type 1 diabetic rats. Exp Neurol. 2011; 232: 299-308. https://doi.org/10.1016/j. expneurol.2011.09.022.

8. Chen J, Venkat P, Zacharek A, Chopp M. Neurorestorative therapy for stroke. Front Hum Neurosci. 2014; 8: 382. https://doi.org/10.3389/fnhum.2014.00382.

9. Christensen M, Schratt GM. microRNA involvement in developmental and functional aspects of the nervous system and in neurological diseases. Neurosci Lett. 2009; 466: 55-62. https://doi.org/10.1016/j.neulet.2009.04.043.

10. Sun Y, Luo ZM, Guo XM, Su DF, Liu X. An updated role of microRNA-124 in central nervous system disorders: a review. Frontiers in Cellular Neuroscience. 2015; 9: 193. https://doi.org/10.3389/fncel.2015.00193.

11. Ponomarev ED, Veremeyko T, Barteneva N, Krichevsky AM, Weiner HL. MicroRNA-124 promotes microglia quiescence and suppresses EAE by deactivating macrophages via the C/EBP-alpha-PU.1 pathway. Nat Med. 2011; 17: 64-70. https://doi.org/10.1038/nm.2266.

12. Willemen HL, Huo XJ, Mao-Ying QL, Zijlstra J, Heijnen CJ, Kavelaars A. MicroRNA-124 as a novel treatment for persistent hyperalgesia. J Neuroinflammation. 2012; 9: 143. https://doi.org/10.1186/1742-2094-9-143.

13. Liu Y, Zhang J, Han R, Liu H, Sun D, Liu X. Downregulation of serum brain specific microRNA is associated with inflammation and infarct volume in acute ischemic stroke. J Clin Neurosci. 2015; 22: 291-5. https:// doi.org/10.1016/j.jocn.2014.05.042.

14. Sun Y, Li Q, Gui H, Xu DP, Yang YL, Su DF, Liu $\mathrm{X}$. MicroRNA-124 mediates the cholinergic antiinflammatory action through inhibiting the production of pro-inflammatory cytokines. Cell Res. 2013; 23: 1270-83. https://doi.org/10.1038/cr.2013.116.

15. He X, Jing Z, Cheng G. MicroRNAs: new regulators of Toll-like receptor signalling pathways. Biomed Res Int. 2014; 2014: 945169. https://doi.org/10.1155/2014/945169.
16. Liu G, Abraham E. MicroRNAs in immune response and macrophage polarization. Arteriosclerosis, thrombosis, and vascular biology. 2013; 33: 170-7. https://doi.org/10.1161/ ATVBAHA.112.300068.

17. Kruit JK, Brunham LR, Verchere CB, Hayden MR. HDL and LDL cholesterol significantly influence betacell function in type 2 diabetes mellitus. Curr Opin Lipidol. 2010; 21: 178-85. https://doi.org/10.1097/ MOL.0b013e328339387b.

18. Williams MD, Nadler JL. Inflammatory mechanisms of diabetic complications. Current Diabetes Reports. 2007; 7: 242-8. https://doi.org/10.1007/s11892-007-0038-y.

19. Zamanian-Daryoush M, DiDonato JA. Apolipoprotein A-I and Cancer. Frontiers in Pharmacology. 2015; 6: 265. https://doi.org/10.3389/fphar.2015.00265.

20. Navab M, Anantharamaiah GM, Reddy ST, Fogelman AM. Apolipoprotein A-I mimetic peptides and their role in atherosclerosis prevention. Nat Clin Pract Cardiovasc Med. 2006; 3: 540-7. https://doi.org/10.1038/ncpcardio0661.

21. Peterson SJ, Husney D, Kruger AL, Olszanecki R, Ricci F, Rodella LF, Stacchiotti A, Rezzani R, McClung JA, Aronow WS, Ikehara S, Abraham NG. Long-term treatment with the apolipoprotein A1 mimetic peptide increases antioxidants and vascular repair in type I diabetic rats. J Pharmacol Exp Ther. 2007; 322: 514-20. https://doi.org/10.1124/ jpet.107.119479.

22. Nissen SE, Tsunoda T, Tuzcu EM, Schoenhagen P, Cooper CJ, Yasin M, Eaton GM, Lauer MA, Sheldon WS, Grines CL, Halpern S, Crowe T, Blankenship JC, et al. Effect of recombinant ApoA-I Milano on coronary atherosclerosis in patients with acute coronary syndromes: a randomized controlled trial. Jama. 2003; 290: 2292-300. https://doi. org/10.1001/jama.290.17.2292.

23. Kruger AL, Peterson S, Turkseven S, Kaminski PM, Zhang FF, Quan S, Wolin MS, Abraham NG. D-4F induces heme oxygenase-1 and extracellular superoxide dismutase, decreases endothelial cell sloughing, and improves vascular reactivity in rat model of diabetes. Circulation. 2005; 111: 3126-34. https://doi.org/10.1161/ CIRCULATIONAHA.104.517102.

24. Soreq H, Wolf Y. NeurimmiRs: microRNAs in the neuroimmune interface. Trends Mol Med. 2011; 17: 54855. https://doi.org/10.1016/j.molmed.2011.06.009.

25. Sun Y, Qin Z, Li Q, Wan JJ, Cheng MH, Wang PY, Su DF, Yu JG, Liu X. MicroRNA-124 negatively regulates LPSinduced TNF-alpha production in mouse macrophages by decreasing protein stability. Acta Pharmacol Sin. 2016; 37 : 889-97. https://doi.org/10.1038/aps.2016.16.

26. Zeng B, Li Z, Chen R, Guo N, Zhou J, Zhou Q, Lin Q, Cheng D, Liao Q, Zheng L, Gong Y. Epigenetic regulation of miR-124 by hepatitis $\mathrm{C}$ virus core protein promotes migration and invasion of intrahepatic cholangiocarcinoma cells by targeting SMYD3. FEBS Lett. 2012; 586: 3271-8. https://doi.org/10.1016/j.febslet.2012.06.049. 
27. Yu JY, Chung KH, Deo M, Thompson RC, Turner DL. MicroRNA miR-124 regulates neurite outgrowth during neuronal differentiation. Exp Cell Res. 2008; 314: 2618-33. https://doi.org/10.1016/j.yexcr.2008.06.002.

28. Ye X, Chopp M, Liu X, Zacharek A, Cui X, Yan T, Roberts C, Chen J. Niaspan reduces high-mobility group box 1/ receptor for advanced glycation endproducts after stroke in type-1 diabetic rats. Neuroscience. 2011; 190: 339-45. https://doi.org/10.1016/j.neuroscience.2011.06.004.

29. Li G, Xu X, Wang D, Wang J, Wang Y, Yu J. Microglial activation during acute cerebral infarction in the presence of diabetes mellitus. Neurol Sci. 2011; 32: 1075-9. https:// doi.org/10.1007/s10072-011-0632-2.

30. Chiba T, Umegaki K. Pivotal roles of monocytes/ macrophages in stroke. Mediators Inflamm. 2013; 2013: 759103. https://doi.org/10.1155/2013/759103.

31. Hori S, Ohtsuki S, Hosoya K, Nakashima E, Terasaki T. A pericyte-derived angiopoietin-1 multimeric complex induces occludin gene expression in brain capillary endothelial cells through Tie-2 activation in vitro. J Neurochem. 2004; 89: 503-13. https://doi.org/10.1111/j.1471-4159.2004.02343.x.

32. Van Itallie CM, Fanning AS, Bridges A, Anderson JM. ZO-1 stabilizes the tight junction solute barrier through coupling to the perijunctional cytoskeleton. Molecular Biology of the Cell. 2009; 20: 3930-40. https://doi.org/10.1091/mbc. E09-04-0320.

33. Kumari R, Willing LB, Patel SD, Baskerville KA, Simpson IA. Increased cerebral matrix metalloprotease -9 activity is associated with compromised recovery in the diabetic $\mathrm{db} / \mathrm{db}$ mouse following a stroke. Journal of neurochemistry. 2011; 119: 1029-40. https://doi. org/10.1111/j.1471-4159.2011.07487.x.

34. Chen J, Cui X, Zacharek A, Cui Y, Roberts C, Chopp M. White matter damage and the effect of matrix metalloproteinases in type 2 diabetic mice after stroke. Stroke. 2011; 42: 445-52. https://doi.org/10.1161/ STROKEAHA.110.596486.

35. Montaner J, Alvarez-Sabín J, Molina C, Anglés A, Abilleira S, Arenillas J, González MA, Monasterio J. Matrix metalloproteinase expression after human cardioembolic stroke: temporal profile and relation to neurological impairment. Stroke. 2001; 32: 1759-66. https://doi. org/10.1161/01.str.32.8.1759.

36. Moxon-Emre I, Schlichter LC. Evolution of inflammation and white matter injury in a model of transient focal ischemia. J Neuropathol Exp Neurol. 2010; 69: 1-15. https://doi.org/10.1097/NEN.0b013e3181c3ce6c.

37. Rosenberg GA. Inflammation and white matter damage in vascular cognitive impairment. Stroke. 2009; 40: S20-3. https://doi.org/10.1161/STROKEAHA.108.533133.

38. Jin R, Yang G, Li G. Inflammatory mechanisms in ischemic stroke: role of inflammatory cells. J Leukoc Biol. 2010; 87: 779-89. https://doi.org/10.1189/jlb.1109766.
39. Tureyen K, Bowen K, Liang J, Dempsey RJ, Vemuganti $R$. Exacerbated brain damage, edema and inflammation in type-2 diabetic mice subjected to focal ischemia. J Neurochem. 2011; 116: 499-507. https://doi. org/10.1111/j.1471-4159.2010.07127.x.

40. King GL. The role of inflammatory cytokines in diabetes and its complications. J Periodontol. 2008; 79: 1527-34. https://doi.org/10.1902/jop.2008.080246.

41. Tran EH, Hoekstra K, van Rooijen N, Dijkstra CD, Owens T. Immune invasion of the central nervous system parenchyma and experimental allergic encephalomyelitis, but not leukocyte extravasation from blood, are prevented in macrophage-depleted mice. J Immunol. 1998; 161: 3767-75.

42. Aloisi F. Immune function of microglia. Glia. 2001; 36: 165-79. https://doi.org/10.1002/glia.1106.

43. Nakajima K, Kohsaka S. Microglia: activation and their significance in the central nervous system. The Journal of Biochemistry. 2001; 130: 169-75. https://doi.org/10.1093/ oxfordjournals.jbchem.a002969.

44. Fischer-Posovszky P, Wang QA, Asterholm IW, Rutkowski JM, Scherer PE. Targeted deletion of adipocytes by apoptosis leads to adipose tissue recruitment of alternatively activated M2 macrophages. Endocrinology. 2011; 152: 3074-81. https://doi.org/10.1210/en.2011-1031.

45. Gordon S. Alternative activation of macrophages. Nat Rev Immunol. 2003; 3: 23-35. https://doi.org/10.1038/nri978.

46. Edwards JP, Zhang X, Frauwirth KA, Mosser DM. Biochemical and functional characterization of three activated macrophage populations. J Leukoc Biol. 2006; 80: 1298-307. https://doi.org/10.1189/jlb.0406249.

47. Busch SA, Hamilton JA, Horn KP, Cuascut FX, Cutrone R, Lehman N, Deans RJ, Ting AE, Mays RW, Silver J. Multipotent adult progenitor cells prevent macrophagemediated axonal dieback and promote regrowth after spinal cord injury. J Neurosci. 2011; 31: 944-53. https://doi. org/10.1523/JNEUROSCI.3566-10.2011.

48. Zanin RF, Braganhol E, Bergamin LS, Campesato LF, Filho AZ, Moreira JC, Morrone FB, Sevigny J, Schetinger MR, de Souza Wyse AT, Battastini AM. Differential macrophage activation alters the expression profile of NTPDase and ecto-5'-nucleotidase. PLoS One. 2012; 7: e31205. https:// doi.org/10.1371/journal.pone.0031205.

49. Hu W, Jiang Z, Zhang Y, Liu Q, Fan J, Luo N, Dong X, Yu X. Characterization of infiltrating macrophages in high glucose-induced peritoneal fibrosis in rats. Mol Med Report. 2012; 6: 93-9. https://doi.org/10.3892/mmr.2012.890.

50. Kigerl KA, Gensel JC, Ankeny DP, Alexander JK, Donnelly DJ, Popovich PG. Identification of two distinct macrophage subsets with divergent effects causing either neurotoxicity or regeneration in the injured mouse spinal cord. J Neurosci. 2009; 29: 13435-44. https://doi.org/10.1523/ JNEUROSCI.3257-09.2009. 
51. Hartmann H, Hoehne K, Rist E, Louw AM, Schlosshauer B. miR-124 disinhibits neurite outgrowth in an inflammatory environment. Cell Tissue Res. 2015; 362: 9-20. https://doi. org/10.1007/s00441-015-2183-y.

52. Hamzei Taj S, Kho W, Riou A, Wiedermann D, Hoehn M. MiRNA-124 induces neuroprotection and functional improvement after focal cerebral ischemia. Biomaterials. 2016; 91: 151-65. https://doi.org/10.1016/j. biomaterials.2016.03.025.

53. Sun Y, Gui H, Li Q, Luo ZM, Zheng MJ, Duan JL, Liu X. MicroRNA-124 protects neurons against apoptosis in cerebral ischemic stroke. CNS Neurosci Ther. 2013; 19: 813-9. https://doi.org/10.1111/cns. 12142.

54. Morris JK, Chomyk A, Song P, Parker N, Deckard S, Trapp BD, Pimplikar SW, Dutta R. Decrease in levels of the evolutionarily conserved microRNA miR-124 affects oligodendrocyte numbers in Zebrafish, Danio rerio. Invert Neurosci. 2015; 15: 4. https://doi.org/10.1007/ s10158-015-0180-1.

55. Like A, Rossini A. Streptozotocin-induced pancreatic insulitis: new model of diabetes mellitus. Science. 1976; 193: 415-7. https://doi.org/10.1126/science. 180605.

56. Zhang L, Zhang RL, Jiang Q, Ding G, Chopp M, Zhang ZG. Focal embolic cerebral ischemia in the rat. Nat Protocols. 2015; 10: 539-47. https://doi.org/10.1038/nprot.2015.036.

57. Chen J, Li Y, Wang L, Zhang Z, Lu D, Lu M, Chopp M. Therapeutic benefit of intravenous administration of bone marrow stromal cells after cerebral ischemia in rats. Stroke. 2001; 32: 1005-11. https://doi.org/10.1161/01.str.32.4.1005.
58. Rogers DC, Campbell CA, Stretton JL, Mackay KB. Correlation between motor impairment and infarct volume after permanent and transient middle cerebral artery occlusion in the rat. Stroke. 1997; 28: 2060-6. https://doi. org/10.1161/01.str.28.10.2060.

59. Schaar KL, Brenneman MM, Savitz SI. Functional assessments in the rodent stroke model. Exp Transl Stroke Med. 2010; 2: 13. https://doi.org/10.1186/2040-7378-2-13.

60. Zhang ZG, Zhang L, Croll SD, Chopp M. Angiopoietin-1 reduces cerebral blood vessel leakage and ischemic lesion volume after focal cerebral embolic ischemia in mice. Neuroscience. 2002; 113: 683-7. https:/doi.org/10.1016/ S0306-4522(02)00175-6.

61. Irving E, Bentley D, Parsons A. Assessment of white matter injury following prolonged focal cerebral ischaemia in the rat. Acta Neuropathologica. 2001; 102: 627-35. https://doi. org/10.1007/s004010100416.

62. Ueno Y, Chopp M, Zhang L, Buller B, Liu Z, Lehman NL, Liu XS, Zhang Y, Roberts C, Zhang ZG. Axonal outgrowth and dendritic plasticity in the cortical peri-infarct area after experimental Stroke. 2012; 43: 2221-8. https://doi. org/10.1161/STROKEAHA.111.646224.

63. Taylor AM, Blurton-Jones M, Rhee SW, Cribbs DH, Cotman CW, Jeon NL. A microfluidic culture platform for CNS axonal injury, regeneration and transport. Nat Methods. 2005; 2: 599-605. https://doi.org/10.1038/ nmeth777.

64. Tamashiro TT, Dalgard CL, Byrnes KR. Primary microglia isolation from mixed glial cell cultures of neonatal rat brain tissue. J Vis Exp. 2012: 3814. https://doi.org/10.3791/3814. 